\title{
RECOMMENDATIONS FOR THE PREVENTION AND CONTROL OF CORONAVIRUS INFECTIONS (SARS-CoV-2) IN LONG TERM CARE FACILITIES
}

\section{Recomendações para prevenção e controle de infecções por coronavírus (SARS-CoV-2) em instituições de longa permanência para idosos}

\section{INTRODUCTION}

The new coronavirus (SARS-CoV-2), which emerged in China in late 2019, quickly became a pandemic. Brazil is heading toward the sustained community transmission phase of SARS-CoV-2, as already evidenced in São Paulo and Rio de Janeiro. The virus is highly contagious, persisting for hours or days on several surfaces. Asymptomatic cases have played an important role in the chain of transmission of the virus and are responsible for up to two thirds of infections. The contingent of undocumented cases that present mild symptoms or are asymptomatic is the epidemiological feature that determines the rapid spread of this respiratory virus. ${ }^{1}$

The older population has been the most vulnerable to severe forms of the disease and progression to death, especially frail older adults, those with comorbidities, and residents in long-term care facilities (LTCFs). Mortality increases linearly with age, being $3.6 \%$ in the $60-69$ age group, $8 \%$ in the $70-79$ age group, and $14.8 \%$ in those over 80 years old. ${ }^{2}$

Older adults living in LTCFs are more vulnerable to COVID-19 for several reasons: ${ }^{3}$

- They are often frail;

- They usually have underlying diseases or comorbidities in advanced stages;

- Advanced age;

- Keep close contact with other people (caregivers and professionals) and cohabitants;

- Spend a lot of time indoors and with equally vulnerable individuals.

\section{OBJECTIVE}

Given the reasons mentioned, the Brazilian Society of Geriatrics and Gerontology (SBGG) aims to describe guidelines and recommendations for the development of institutional action plans to prevent and contain the dissemination of COVID-19 in LTCFs.

\section{GENERAL GUIDELINES}

LTCFs should prepare action and surveillance plans adapted to the characteristics of each institution, in order to avoid, as much as possible, the appearance of local contamination and outbreaks of the disease caused by COVID-19..$^{4-6}$

This plan should include the preventive and behavioral actions as well as establish the needs for personal protective equipment (PPE), supply of hygiene materials, and disinfectant solutions. We emphasize that it is important to ensure the continuity of care for institutionalized older adults even in the face of challenges related to the foreseeable lack of health care professionals who will be kept away from their duties due to isolation by disease.

\section{SPECIFIC GUIDELINES AND RECOMMENDATIONS}

- Organize action plans for prevention and care for older adults living in the LTCFs;

- Provide the staff with training on the programmed measures;

- Reinforce onsite hygiene practices and hand hygiene and protection protocols for residents and employees;

- With the assistance team, establish procedures of identification, evaluation, isolation, and conducts in the face of suspected and confirmed cases in the institution;

- Organize areas for respiratory isolation of symptomatic residents;

- Maintain natural ventilation in the rooms and reduce the use of air conditioners to the strictly necessary;

- Suspend visits to institutions indefinitely; 
- If an employee arrives at work with respiratory symptoms or fever you should immediately send him or her home;

- Restrict group activities and circulation in collective areas;

- Conduct health education training activities for health care professionals ( $\mathrm{HCPs}$ ) of the institution and residents on preventive measures (hand hygiene, use of alcohol gel) and the use of personal protective equipment (PPE) when indicated;

- Sanitize hands before and immediately after any touching on the resident, even when PPE (gloves) are used. After wearing gloves, hand hygiene is also mandatory;

- If hands are visibly clean, their hygiene can be performed with alcohol-based products (70\% alcohol hand sanitizer gel). If they are dirty or stained with liquids, it should be done with water and antiseptic soap;

- Dispensers with 70\% alcohol hand sanitizer gel should be available at the entrance of LTCFs, in waiting rooms, reception, and bedrooms to sanitize the hands of everyone moving around;

- In all bathrooms and washbasins, soap must be available for hand sanitizing, paper towels, and lidded pedal-operated bins;

- Clean hands with soap and water or 70\% alcohol hand sanitizer gel before and after contact with residents, after contact with contaminated surfaces or equipment, and after removal of PPE;

- The use of gloves does not exempt from adequate hand hygiene after their removal. They should always be changed after individual use, and hand hygiene must be done after removal and before new ones are put on;

- Observe the recommendations provided for in Regulatory Standard 32 (NR 32) for occupational safety and health in health care services (available on: http://trabalho.gov.br/images/Documentos/SST/NR/ NR32.pdf);

- Nails should be short and tidy;

- Avoid the use of rings, bracelets, watches or other adornments;

- Hair should not exceed shoulder height; if it does, it should be bind or covered with a protective cap;

- The use of surgical masks is indicated for symptomatic patients and for HCPs in direct contact with the individual;

- It is the responsibility of the institution to provide masks and tissues for people with coughs and other respiratory symptoms;
- Always discard the mask at each use and sanitize the hand after its disposal;

- After using a tissue, throw it away immediately and wash your hands;

- N95 and PFF2 respiratory protection masks have their use restricted to HCPs in situations of potential aerosol contamination (orotracheal intubation, aspiration and airway management);

- Consider designating an employee to check and encourage hand hygiene and the correct use of masks and PPE by residents, family members, and other employees;

- Attach signs to the door or wall outside the resident's bedroom with a clear description of the types of precautions and PPE required;

- Place a waste bin with a pedal-operated lid in the resident's bedroom so that workers can easily dispose of PPE.

\section{SPECIFIC CIRCUMSTANCES}

\section{Health care professionals}

- It is recommended that HCPs with respiratory symptoms be kept away even before the identification of COVID-19 in the community. The professional must seek the closest medical unit to define referrals and isolation, according to the guidelines of the Brazilian Ministry of Health;

- During direct care to a resident with a suspected or confirmed COVID-19 condition, the HCP should use the following PPE: cap, goggles, surgical mask, gloves, and disposable apron. Wear them immediately before contact with the resident or surfaces and remove them immediately after use, sanitizing the hands before and immediately after removing the equipment;

- Report all suspected cases of COVID-19 immediately.

\section{Residents with respiratory symptoms}

- As a general rule, all residents with acute respiratory symptoms should have their movement around the LTCF restricted as much as possible, stay in a dormitory with good ventilation and, ideally, with their own bathroom and contact precautions;

- Visits to common areas should be kept to a minimum. If necessary, the institutionalized should wear a surgical mask and be more than 2 meters from the other residents. For this older person, the protocols 
established by government agencies for the prevention of airborne diseases (such as influenza, for example) must be strictly followed;

- It is recommended that all residents with respiratory symptoms be assisted by a HCP with a surgical mask.

Cleaning and disinfection of surfaces and spaces

- It is essential to ensure adequate and frequent cleaning of surfaces and spaces;

- The procedure to clean and disinfect surfaces and contact areas with the patient will be done according to the usual routine of cleaning and disinfection of LTCFs;

- The cleaning staff should receive training and information before the first entry into the dormitory and use appropriate PPE;

- The process of cleaning and disinfection of all surfaces should be performed with 70\% alcohol hand sanitizer gel for shared materials or $1 \%$ sodium hypochlorite. In case the surface presents visible organic matter, the excess dirt must be removed initially with paper/absorbent tissue and later cleaned and disinfected;

- Regularly clean frequently touched surfaces and equipment that is shared (handles, TV controls, protective bars, handrails, etc.);

- Used disposable material should be placed in a lidded waste container labeled with precise warnings of infectious material.

\section{Clothes Processing}

- The same process established for clothes coming from other patients in general can be followed, with minimum moving and handling of the clothes.

\section{Admission of new resident in the LTCF}

- In case of admission of a new resident to the LTCF or post-hospitalization readmission, symptoms of respiratory infection should be actively assessed on admission and, if necessary, appropriate isolation measures should be implemented, following the recommendations mentioned in this document.

\section{Actions in the face of COVID-19 contacts and cases}

- If the older adult resident had contact with a COVID-19 case, keep him in preventive isolation at the LTCF itself and notify the municipality's health surveillance and public health services about the case;
- The older adult resident with indication of respiratory isolation should remain in a dormitory with good ventilation and ideally with his/her own bathroom for 14 days;

- Visits to common areas should be restricted to the minimum possible and, if necessary, the institutionalized individuals should wear a surgical mask;

- Older people who share dormitories with those who have presented symptoms do not need to be relocated, as it is understood that they have already been exposed and should be managed as described above;

- Perform active surveillance for respiratory symptoms at LTCFs;

- It is not necessary to transfer the older person to another health service if the general condition is stable and there are no criteria of severity.

Complementary and additional information can be found on the websites and in the documents of the health instances of your municipality, your state, or the Brazilian Ministry of Health.

Last statement update

Issued on March 17, 2020.

Special Commission COVID-19, Brazilian Society of Geriatrics and Gerontology (Sociedade Brasileira de Geriatria e Gerontologia - SBGG)

\section{Paulo José Fortes Villas Boas}

Member of the special Commission COVID-19 of the SBGG

Mariana Gegenheimer Bremenkamp Member of the Special Commission COVID-19 of the SBGG

\section{Jarbas de Sá Roriz Filho}

Member of the Special Commission COVID-19 of the SBGG

\section{Maisa Carla Kairalla}

Coordinator of the Special Commission COVID-19 of the SBGG

Daniel Christiano de Albuquerque Gomes Member of the Special Commission COVID-19 of the SBGG 
Renato Gorga Bandeira de Mello Scientific Director of the SBGG

\section{Carlos André Uehara}

President of the SBGG

\section{REFERENCES}

1. Li R, Pei S, Chen B, Song Y, Zhang T, Yang W, et al. Substantial undocumented infection facilitates the rapid dissemination of novel coronavirus (SARS-CoV2). Science. 2020. http://doi.org/10.1126/ science.abb3221

2. Zhou F, Yu T, Du R, Fan G, Liu Y, Liu Z, et al. Clinical course and risk factors for mortality of adult inpatients with COVID-19 in Wuhan, China: a retrospective cohort study. Lancet. 2020;395(10229):105462. http://doi.org/10.1016/50140-6736(20)30566-3

3. D'Adamo H, Yoshikawa T, Ouslander JG. Coronavirus Disease 2019 in Geriatrics and Long-term Care: The ABCDs of COVID-19: COVID-19 in Geriatrics and Long-Term Care. J Am Geriatr Soc [Internet]. 2020 [Accessed in 27 mar. 2020]. Available from: http://doi.wiley.com/10.1111/ jgs.16445

4. España. Ministerio de Sanidad. Recomendaciones a residencias de mayores y centros sociosanitarios para el COVID-19 [Internet].
España: Ministerio de Sanidad; 2020 [Accessed in 27 mar. 2020]. Available from: https://www.mscbs.gob.es/profesionales/ saludPublica/ccayes/alertasActual/nCov-China/documentos/ Centros_sociosanitarios.pdf

5. World Health Organization. Infection Prevention and Control guidance for Long-Term Care Facilities in the context of COVID-19 [Internet]. World Health Organization; 2020 [Accessed in 27 mar. 2020]. Available from: https://apps.who.int/iris/bitstream/ handle/10665/331508/WHO-2019-nCoV-IPC_long_term_care2020.1-eng.pdf

6. Wright D. Guidance for Infection Control and Prevention of Coronavirus Disease 2019 (COVID-19) in Nursing Homes [Internet]. Centers for Medicare \& Medicaid Services; 2020 [Accessed in 27 mar. 2020]. Available from: https://www.cms.gov/files/document/qso-20-14-nhrevised.pdf 